\title{
REFLEXÕES SOBRE A COBRANÇA PELOS SERVIÇOS DE GESTÃo DOS RESÍDUOS SÓLIDOS EM MUNICIIPIOS CEARENSES CONSORCIADOS
}

\section{REFLECTIONS ON CHARGES BY SOLID WASTE MANAGEMENT SERVICES IN CONSORTED TOWNS FROM CEARÁ}

Carlos Vangerre de Almeida Maia ${ }^{1}$

Anny Kariny Feitosa ${ }^{2}$

Vanessa Sandyla da Silva Rocha ${ }^{3}$

Renata Saraiva Vidal ${ }^{4}$

RESUMO

Tiago Regis de Melo Alves ${ }^{5}$

O Plano Estadual de Resíduos Sólidos do Ceará (PERSCE) determina que, até 2020, 20\% dos seus municípios estejam consorciados e realizem cobrança pelos serviços de manejo de resíduos sólidos desvinculadamente do Imposto Predial Territorial Urbano (IPTU). O Consórcio de Gestão Integrada de Resíduos Sólidos - Vale do Jaguaribe (CGIRS-VJ) operará equipamentos de transbordo, transporte e disposição final por meio da iniciativa privada, cujo dispêndio poderá ser repassado aos usuários. Esse trabalho verificou se as variáveis sugeridas para a possível base de cálculo da cobrança do serviço na região estão entre as mais usuais; e comparou indicadores socioeconômicos dos entes do CGIRS-VJ (Grupo I) com de outros municípios igualmente consorciados e que já realizem a cobrança dessa maneira (Grupo II). Através do Sistema Nacional de Informações sobre Saneamento, identificou-se quais os municípios brasileiros estão consorciados e realizam a cobrança de maneira desvinculada do IPTU. As variáveis que compõem as bases de cálculo foram consultadas nas legislações municipais. Constatou-se que as variáveis sugeridas para compor a base de cálculo dos entes do CGIRS-VJ estão entre as mais recorrentes e há diferença significativa entre as médias do IDH e do PIB per capita dos integrantes do CGIRS-VJ, inferiores às médias dos municípios do Grupo II.

Palavras-chave: Sustentabilidade. Indicadores. Consórcios públicos.

\footnotetext{
${ }^{1}$ Mestre em Desenvolvimento e Meio Ambiente - Universidade Federal do Piauí. Ceará. Brasil. E-mail: cvamaia@yahoo.com.br. ORCID: https://orcid.org/0000-0002-4800-5404

${ }^{2}$ Doutora em Ambiente e Desenvolvimento. Professora do Instituto Federal de Ciências, Educação e Tecnologia do Ceará. Campus Iguatu. Ceará. Brasil. E-mail: akfeitosa@hotmail.com. ORCID: https://orcid.org/0000-0002$\underline{5745-2660}$

${ }^{3}$ Técnica em Meio Ambiente. Instituto Federal de Ciências, Educação e Tecnologia do Ceará. Campus Iguatu. Ceará. Brasil. E-mail: renatasaraiva8@hotmail.com

${ }^{4}$ Técnica em Meio Ambiente. Instituto Federal de Ciências, Educação e Tecnologia do Ceará. Campus Iguatu. Ceará. Brasil. E-mail: sandylavanessa2014@gmail.com

${ }^{5}$ Bacharel em Direito. Procuradoria Geral do Município de Quixeré. Ceará. Brasil. E-mail: tiagoregisadv@gmail.com ORCID: https://orcid.org/0000-0001-9107-9102
} 


\begin{abstract}
The State Plan of Solid Waste of Ceará (SPSWCE) determines that, by 2020, 20\% of its municipalities are in consortium and charge for solid waste management services separately from the Urban Land Tax (ULT). The Integrated Solid Waste Management Consortium - Vale do Jaguaribe (ISWMC-VJ) will operate transhipment, transportation and final disposal equipment through the private initiative, the expenditure of which may be passed on to users. This study verified whether the variables suggested for the possible basis for calculating service charges in the region are among the most usual and it compared socioeconomic indicators of ISWMC-VJ entities (Group I) with other municipalities that are similarly consortium and that collect in this way (Group II). Through the National Sanitation Information System, it was identified which Brazilian municipalities are in consortium and are charging the property separately from the property tax. The variables that make up the calculation bases were consulted in the municipal legislations. It was found that the variables suggested to compose the basis of calculation of ISWMC-VJ entities are among the most recurrent and significant difference between the average HDI and GDP per capita of ISWMC-VJ members, lower than the average of the municipalities of the state from Group II.
\end{abstract}

Key-words: Sustainability. Indicators. Public consortium.

Como citar este artigo: MAIA, C. V. A. et al. Reflexões sobre a cobrança pelos serviços de gestão dos resíduos sólidos em municípios cearenses consorciados. DRd - Desenvolvimento Regional em debate, v. 9, p. 668-682, 28 out. 2019.

DOI: https://doi.org/10.24302/drd.v9i0.2226

Artigo recebido em: 04/08/2019

Artigo aprovado em: 11/10/2019

Artigo publicado em: 29/10/2019

\title{
INTRODUÇÃO
}

O saneamento básico brasileiro, a partir da Lei n 11.445 Brasil (2007), foi considerado como um conjunto de serviços, infraestruturas e instalações operacionais de abastecimento de água, esgotamento sanitário, drenagem, manejo de águas pluviais, limpeza pública e manejo de resíduos sólidos, que devem ser prestados sob os princípios da universalização e eficiência econômico-financeira, dentre outros, de titularidade municipal, com estímulo à gestão associada.

A Sustentabilidade Econômica e Financeira (SEF) dos serviços de saneamento deverá observar: prioridade para o atendimento das funções essenciais relacionadas à saúde pública; ampliação do acesso dos cidadãos e localidades de baixa renda aos serviços e, geração dos recursos necessários para realização dos investimentos, objetivando o cumprimento das metas e objetivos do serviço (BRASIL, 2007).

DRd - Desenvolvimento Regional em debate (ISSNe 2237-9029) 
Para os serviços de limpeza urbana e de manejo de resíduos sólidos urbanos, as formas de cobrança devem levar em conta a adequada destinação dos resíduos coletados; o nível de renda da população da área atendida; as características dos lotes urbanos e as áreas que podem ser neles edificadas; peso ou o volume médio coletado por habitante ou por domicílio, para a formulação de sua base de cálculo (BRASIL, 2010).

O Plano Nacional de Saneamento Básico estabeleceu que 26\% dos municípios nordestinos, até 2018, deveriam instituir algum tipo de cobrança pelos serviços de gestão e manejo de resíduos sólidos; já o Plano Estadual de Resíduos Sólidos do Ceará (PERSCE) estima em $20 \%$ o número de municípios que deverão efetuar cobrança de maneira desvinculada do IPTU, que devem estar consorciados e com seus lixões encerrados até 2020 (CEARÁ, 2016).

Na Região Metropolitana de Sobral (RMS) e no Vale do Jaguaribe há 30 municípios organizados em dois consórcios públicos horizontais, aos quais o Governo do Estado aportou recursos para promover a Gestão Integrada de Resíduos Sólidos (GIRS), seja em ações estruturantes ou a própria construção de equipamentos para transbordo e disposição final, cuja operação deverá ser privada, podendo repercutir em novo dispêndio aos cofres públicos e deflagrar a cobrança pelo serviço ao usuário.

Logo, esse trabalho verificou se as variáveis propostas para a possível base de cálculo da cobrança pelos serviços nos municípios Jaguaribanos são usuais em municípios que já realizam cobrança de maneira desvinculada ao IPTU, além de comparar indicadores socioeconômicos dos entes do Consórcio de Gestão Integrada de Resíduos Sólidos do Vale do Jaguaribe (CGIRS-VJ) com a secção desses retromencionados municípios brasileiros que estejam consorciados.

\section{ASPECTOS HISTÓRICOS PARA A CONSTITUIÇÃO DO CGIRS-VJ}

Há 184 municípios e cerca de 300 lixões no Ceará, que já deveriam estar desativados desde 2014. Não obstante, o Senado aprovou o Projeto de Lei 3261/2019, que postergará esse prazo até 31 de dezembro de 2020, podendo ser ampliado, de maneira escalonada, em função do porte populacional, desde que haja plano regional ou municipal para a gestão integrada de resíduos sólidos, além de mecanismos de cobrança que garantam a SEF (BRASIL, 2019).

A construção e operação de equipamentos para atender a disposição adequada para de maneira individualizada é economicamente onerosa, especialmente para pequenos municípios, podendo inviabilizar as boas práticas dessa etapa da gestão e manejo de resíduos sólidos.

Assim, os consórcios públicos se apresentam como uma possibilidade para superar esse desafio, sendo que o Ceará já aponta esse arranjo antes mesmo da promulgação da Lei Federal $n^{\circ}$ 11.405, Brasil (2005), mediante a Lei Estadual n 13.103, Ceará (2001).

Em 2005, o Estado contratou um estudo para verificar a viabilidade do tratamento e disposição de resíduos sólidos em seu território, tendo o indicativo de agrupar os 184 municípios cearenses em 30 consórcios, dos quais, entre 2008 e 2010, 22 se constituíram sob o nome de Consórcio Municipal para Aterro de Resíduos Sólidos - COMARES - alterando 
apenas a unidade, identificada pelo município sede, objetivando a construção de aterros sanitários.

Desses, em 2009, constituíram-se o COMARES-UL, com os seguintes entes Limoeiro do Norte (sede), Alto Santo, Ereré, Iracema, Morada Nova, Palhano, Potiretama, Quixeré, Russas, São João do Jaguaribe e Tabuleiro do Norte; bem como o COMARES-UAR, com sede em Aracati, tendo como consortes Fortim, Jaguaruana, Icapuí e Itaiçaba.

As alterações provocadas pela Política Nacional de Resíduos Sólidos (PNRS) fizeram com que o Ceará, em 2011, realizasse um estudo inerente à regionalização para a GIRS, que resultou em 14 regiões. Ademais, houve atualização da Política Estadual de Resíduos Sólidos, através da Lei Estadual n ${ }^{\circ}$ 16.032/2016.

De acordo com Melo (2017), esse estudo ponderou sobre uma mensuração de escala mais adequada, considerando sete critérios: população urbana, existência de uma unidade regional, malha rodoviária, distância média entre as sedes, existência de unidades de conservação, relevo e a produção de resíduos, que mesmo aventando sobre a possibilidade de fusão de consórcios, o retromencionado estudo não explicava como proceder.

Em 2017, através do Projeto de Desenvolvimento Urbano de Polos Regionais - Vale do Jaguaribe e Vale do Acaraú ${ }^{6}$, houve a alocação de recursos financeiros e assessoria técnica para a construção de equipamentos, em prol da GIRS na RMS e no Vale Jaguaribe, bem como foram traçadas metas, em um Termo de Ajustamento de Conduta, celebrado entre o Ministério Público Estadual, Secretarias das Cidades, Secretaria do Meio Ambiente e entes do COMARES-UL.

Já em 2018, considerando o que propunha o COMARES-UL e o que vem se implantando na região, a Assembleia dos Prefeitos autorizou que os instrumentos legais fossem ratificados pelas suas Câmaras Municipais, alterando o nome e objetivos do Consórcio, surgindo, o Consórcio de Gestão Integrada de Resíduos Sólidos - Vale do Jaguaribe (CGIRS$\mathrm{VJ})^{7}$, que aumentou seu raio de atuação, com o ingresso dos municípios advindos do COMARES-UAR - Itaiçaba e Jaguaruana, totalizando, a partir de então, 13 municípios, destacado na Figura 1.

\footnotetext{
${ }^{6}$ Esse projeto, cujo Contrato de Empréstimo no 2628/OC-BR fora assinado no dia 02 de setembro de 2013, entre o Governo do Estado do Ceará e o Banco Interamericano de Desenvolvimento, mira impulsionar o desenvolvimento regional sustentável, apoiado por práticas que permitam a gestão e o gerenciamento integrado dos resíduos sólidos.

${ }^{7}$ A fusão de consórcios públicos depende da aprovação de um aditivo aos contratos de cada consórcio original por parte de todos os partícipes, cujo consórcio fusionado poderá sofrer alteração em seu nome. Na prática, isso pode ser similar à constituição de um novo consórcio público e extinção dos anteriormente existentes (MELO, 2017).
} 
Figura 1 - Consórcios no Ceará em 2018, com ênfase aos entes do CGIRS-VJ.
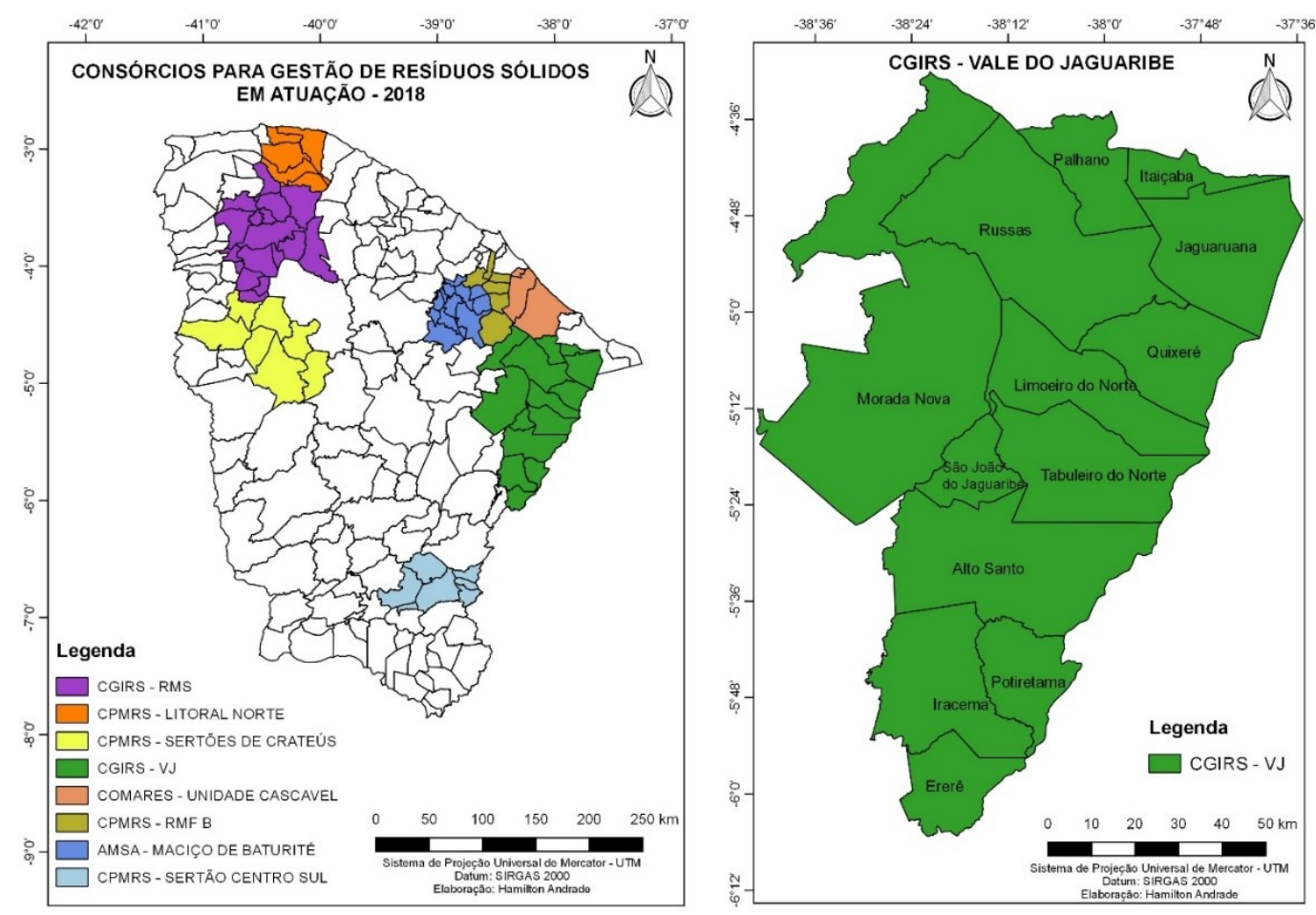

Fonte: Autores (2019)

\section{MATERIAL E MÉTODOS}

A presente pesquisa foi conduzida mediante quatro etapas, cujo início foi desencadeado por meio de pesquisa exploratória e documental, no intuito de traçar o perfil socioeconômico dos consortes do CGIRS-VJ (Grupo I), utilizando os seguintes indicadores: IDH, PIB per capta, índice de Gini e população; seguido de busca junto ao Sistema Nacional de Informações em Saneamento (SNIS) (BRASIL, 2019), através dos indicadores FN 201 e FN 202, para identificar quais municípios brasileiros realizavam cobrança desvinculada do IPTU.

A seguir, averiguou-se quais as variáveis utilizadas em suas bases de cálculo para essa forma de cobrança, através do acesso as legislações municipais, obtidas mediante consulta aos sites das Câmaras e Prefeituras desses municípios, contato telefônico e por e-mail, além de sites de busca, considerando os seguintes descritores: taxa ou tarifa; lixo ou resíduos sólidos; nome do município, sendo agrupadas de maneira similar ao proposto por Ventura e Shibassaki (2016).

Por fim, também através do SNIS, mediante o indicador PO-042, constatou-se quais desses municípios fazem parte de algum consórcio intermunicipal de resíduos sólidos. Aqueles que participam e possuem população compreendida na faixa populacional dos entes do CGIRSVJ compuseram o Grupo II, cujas médias dos seus indicadores socioeconômicos foram comparadas aos dos entes do Grupo I, mediante Teste $t$ para amostras independentes $(\mathrm{p}<0,05)$.

DRd - Desenvolvimento Regional em debate (ISSNe 2237-9029) 


\section{RESULTADOS E DISCUSSÃO}

Segundo Pereira e Moreira (2016), no Brasil, há 5631 consórcios públicos - dos quais, o saneamento básico é o quarto maior objeto de consorciamento: 7,57\% do total; bem como há mais municípios que fazem parte de algum consórcio público do que o contrário, o que não ocorre no Nordeste brasileiro, apontando a falta de tradição desse tipo de arranjo nessa região.

O CGIRS-VJ é um dos oito consórcios públicos para a GIRS em atividade no Ceará, em 2018, composto por 13 municípios, de natureza pública e do tipo horizontal, albergando cerca de 358 mil habitantes, gerando, aproximadamente, 314,1 toneladas de resíduos por dia (CEARÁ, 2018), cujas características socioeconômicas de seus entes constam na Tabela 1.

Tabela 1 - Características socioeconômicas dos entes do CGIRS-VJ

\begin{tabular}{|c|c|c|c|c|}
\hline M unicip io & População estimad a (2018) & $\begin{array}{c}\text { ID H } \\
(2010)\end{array}$ & $\begin{array}{c}\text { Gini } \\
(2010)\end{array}$ & PIB per capita (2016) \\
\hline A1to $S$ anto & 17.096 & 0.601 & 0.4819 & $7.889,81$ \\
\hline Ererê & 7.211 & 0.610 & 0.4701 & $7.192,11$ \\
\hline Iracema & 14.227 & 0.652 & 0.5562 & $8.836,54$ \\
\hline Itaiçaba & 7.787 & 0.656 & 0.4446 & $7.946,66$ \\
\hline Jaguaruana & 33.967 & 0.624 & 0.4723 & $11.031,70$ \\
\hline Limoeiro do Norte & 59.278 & 0.682 & 0.5055 & $15.842,69$ \\
\hline Morada Nova & 62.069 & 0.610 & 0.5264 & $12.217,14$ \\
\hline Palha no & 9.348 & 0.638 & 0.4700 & $6.910,12$ \\
\hline Potiretama & 6.400 & 0.604 & 0.4975 & $7.864,06$ \\
\hline Quixeré & 22.008 & 0.622 & 0.4486 & $14.899,86$ \\
\hline Russas & 76.884 & 0.674 & 0.4696 & $12.125,65$ \\
\hline São João do Jaguaribe & 7.691 & 0.654 & 0.511 & $12.618,89$ \\
\hline Tabuleiro do Norte & 30.695 & 0.645 & 0.5413 & $9.294,10$ \\
\hline
\end{tabular}

Fonte: IBGE (2019). Adaptado.

Para o Programa das Nações Unidas, o IDH busca aferir a qualidade de vida de uma população, mediante análise conjunta entre renda, educação e longevidade de uma população, em uma escala que varia entre 0 e 1 . Os entes do CGIRS-VJ, possuem médio desenvolvimento humano, com valores entre 0,600 e 0,699 , sendo Limoeiro do Norte o melhor $(0,682)$, mesma média estadual, e Alto Santo, o menor $(0,601)$.

Um dos critérios utilizados para a construção desse indicador é o nível de saúde, refletindo a expectativa de vida da população, onde os serviços de saneamento básico são fatores condicionantes e determinantes, consagrados pela Constituição Federal.

Precárias condições sanitárias desencadeiam doenças relacionadas ao saneamento ambiental inadequado, como as vetorizadas pelo Aedes aegypti. Maia et al. (2019), em Jaguaruana-CE, identificaram correlação moderada e inversamente proporcional entre a quantidade de depósitos positivos para o vetor e o acesso à coleta de resíduos, de acordo com 
os setores censitários; já Sobral e Sobral (2019), em Recife-PE, constaram que o incremento de 1.000 toneladas na coleta de resíduos doméstico provoca redução de 0,032 casos de dengue.

Ainda sobre a intrinsecidade entre essa variável e os resíduos sólios, no Paraná, verificou-se que são nos municípios com menores IDH onde estão os maiores índices de destinação dos Resíduos Sólidos Urbanos (RSU) para os lixões a céu aberto ${ }^{8}$.

O índice de Gini busca aferir a concentração de renda, comparando a renda entre os $20 \%$ mais pobres e os $20 \%$ mais ricos, representado por valores entre 0 (maior distribuição) e 1 (maior concentração). Os dados da Pesquisa Nacional de Amostra Domiciliar Contínua Anual, de 2017, apontam agravamento do quadro da desigualdade de renda em 15 Estados brasileiros, sendo o Ceará o sétimo mais desigual do país - 0,560, mesmo assim, inferior ao valor encontrado em 2010, que foi de 0,610 (BRASIL, 2018).

Nos entes do CGIRS-VJ, esse índice se apresentou inferior ao valor estadual, variando entre 0,4446 (Itaiçaba) a 0,5562 (Iracema). Saianni et al. (2013), avaliando a desigualdade de renda nos municípios brasileiros, constataram que ela é capaz de explicar parcialmente a desigualdade no aceso ao serviço de coleta de resíduos.

O PIB per capita, que é o resultado da divisão entre a riqueza produzida por um município e sua população, na região, variou de R\$ 6.910,12 (Palhano), $119^{\circ}$ do Estado, a R\$ 15.842,69 (Limoeiro do Norte), $11^{\circ}$, único dos consortes a superar a média estadual, que é de R\$ 15.437,75, metade do PIB per capita nacional (CEARÁ, 2018a).

Marder et al. (2018), em municípios pertencentes a um consórcio intermunicipal para a GIRS, no Rio Grande do Sul, encontraram relação diretamente proporcional entre essa variável e a geração de resíduos, ao passo que Pisani Jr. et al (2018) encontraram correlação entre a população municipal e a taxa de geração per capita de resíduos sólidos urbanos em municípios paulistas.

Considerando essas duas últimas variáveis de maneira sinérgica, Saianni e Tonetto Jr (2014), constataram relação diretamente proporcional ao porte do município e ao seu PIB per capita e a taxa de coleta domiciliar de resíduos e existência de aterros, logo os municípios com menor porte populacional são os que possuem menor índice de coleta domiciliar e com locais para disposição ambientalmente adequada - aterros sanitários - logo, sendo necessário o ganho em economia de escala, algo possível de ser obtido mediante o consorciamento.

No CGIRS-VJ, 61,5\% de seus entes possuem até 30 mil habitantes, realidade comum no Nordeste $(80,6 \%)$, que, devido a escala, dificultaria e oneraria bastante soluções individuais. Estudo do Banco Nacional de Desenvolvimento Econômico e Social (BNDES, 2015), aponta que, nessa região, seria necessário investir cerca de R $\$ 1,05$ bilhões $(42,48 \%$ do investimento necessário para todo o país), para a construção de 154 aterros sanitários dos mais diversos portes, considerando o encerramento de todos os lixões até 2019. Salienta-se que os municípios precisariam estar consorciados, em um raio médio de $100 \mathrm{Km}$, para ser viável.

De acordo com Menezes, Saiani e Toneto Jr (2014), o Nordeste é a região brasileira com maior número de municípios e $93 \%$ deles não possuem aterros sanitários. Ao estipularem preços

\footnotetext{
${ }^{8}$ Trabalho com autoria não identificada, mas disponível em: http://www.abep.org.br/xxencontro/files/paper/451575.pdf.
} 
mínimos médios para todas as regiões, em função do porte populacional, os autores identificaram que os retromencionados preços são sempre menores para arranjos consorciados, do que para soluções individuais.

A disposição final ambientalmente adequada dos resíduos e rejeitos nos entes do CGIRS-VJ, cuja distância entre o município Sede (Limoeiro do Norte) e os município mais extremo (Ereré) é de cerca de $130 \mathrm{Km}$, passará por equipamentos - Estações de Transbordo e Central de Tratamento de Resíduos - que deve ser operada por meio da iniciativa privada, com custo estimado na ordem de R \$ 7,5 milhões em seu primeiro ano de operação (CEARÁ, 2018b).

Considerando que esses municípios não possuem, atualmente, dispêndio financeiro com esse tipo de operação, é possível que haja o repasse, de maneira parcial ou integral, aos munícipes, acarretando na cobrança pelo serviço, que, de acordo com Brasil (2019), é realizada em $46,3 \%$ dos municípios brasileiros, recuperando $54,6 \%$ do investimento, cuja prática é mais recorrente nos maiores municípios, mormente sob a forma de taxa ${ }^{9}$.

A cobrança pelo manejo de resíduos sólidos, em alguns casos, é criticada pela população, por onerar o orçamento familiar, porém, é possível constatar que a sua implantação também repercute positivamente na ecoeficiência da gestão de resíduos (MANNI; RUNHAAR, 2014; YUAN; HUANG; XU, 2016).

Dos municípios brasileiros que realizam cobrança, 224 o fazem de forma diferenciada do IPTU, sendo que $147(65,6 \%)$ são da região Sul; 45 (20,1\%) do Sudeste; 21 (9,4\%) do Centro-Oeste; $6(2,7 \%)$ do Norte e $5(2,2 \%)$ da região Nordeste.

Nesse trabalho, foram identificadas legislações específicas em 57 municípios, onde, do Nordeste, só figuravam duas capitais, coadunando com Brasil (2019), sobre a baixa tradição desse tipo de cobrança nos municípios nordestinos, bem como a predominância dessa prática em municípios de maior porte populacional, cuja listagem dos municípios, consta no Quadro 1.

\footnotetext{
${ }^{9} \mathrm{~A}$ taxação, mediante a Constituição Federal (art. 145, II), possui duas hipóteses: (I) o exercício regular do poder de polícia (poder fiscalizatório da administração pública); (II) a utilização efetiva ou potencial de um serviço público específico e divisível, prestado ao contribuinte ou colocado à sua disposição, cuja Súmula Vinculante de $\mathrm{n}^{\circ}$ 19, do Supremo Tribunal Federal, declarou constitucionalidade quanto à taxação pelos serviços de resíduos sólidos.
} 
Reflexões sobre a cobrança pelos serviços de gestão dos resíduos sólidos em municípios cearenses consorciados

Quadro 1 - Amostra de municípios que realizam cobrança pelo serviço de manejo de resíduos sólidos, de maneira desvinculada do IPTU

\begin{tabular}{|c|c|c|c|c|}
\hline \multicolumn{5}{|c|}{ Municípios } \\
\hline Altamira (PA) & Colombo (PR) & João Pessoa (PB) & Palhoça (SC) & $\begin{array}{c}\text { Santana do Itararé } \\
(\mathrm{PR})\end{array}$ \\
\hline Aparecida (SP) & $\begin{array}{c}\text { Governador Valadares } \\
\text { (MG) }\end{array}$ & Lages (SC) & $\begin{array}{l}\text { Paranavaí } \\
\text { (PR) }\end{array}$ & $\begin{array}{c}\text { São João Batista } \\
\text { (MG) }\end{array}$ \\
\hline Araraquara (SP) & Guaçuí (ES) & Luiz Alves (SC) & $\begin{array}{l}\text { Paraisópolis } \\
\text { (MG) }\end{array}$ & $\begin{array}{l}\text { São José dos } \\
\text { Pinhais (PR) }\end{array}$ \\
\hline Atibaia (SP) & Ibiporã (PR) & Mandirituba (PR) & Pelotas (RS) & Sete Lagoas (MG) \\
\hline $\begin{array}{l}\text { Bom Jesus dos } \\
\text { Perdões (SP) }\end{array}$ & Iguatemi (MS) & Matinhos (PR) & Penha (SC) & $\begin{array}{c}\text { Tangará da Serra } \\
(\mathrm{MT})\end{array}$ \\
\hline $\begin{array}{c}\text { Balneário Camboriu } \\
\text { (SC) }\end{array}$ & Imaruí (SC) & Meleiro (SC) & Piên (PR) & Teresina $(\mathrm{PI})$ \\
\hline Bataguassu (MS) & Inocência (MS) & Monte Carlo (SC) & Piraquara (PR) & Tijucas do Sul (PR) \\
\hline Blumenau (SC) & Irineópolis (SC) & $\begin{array}{l}\text { Montes Claros } \\
\text { (MG) }\end{array}$ & $\begin{array}{l}\text { Pomerode } \\
\quad \text { (SC) }\end{array}$ & Vilhena (RO) \\
\hline Caraá (RS) & Içara (SC) & Nioaque (MS) & $\begin{array}{l}\text { Porto Vitória } \\
\text { (PR) }\end{array}$ & Viçosa (MG) \\
\hline Carbonita (MG) & Itajaí (SC) & $\begin{array}{l}\text { Novo Horizonte } \\
\text { (SC) }\end{array}$ & $\begin{array}{l}\text { Quitadinha } \\
\text { (PR) }\end{array}$ & \\
\hline Carangola (MG) & Itaúna (MG) & Nova Veneza (SC) & $\begin{array}{l}\text { Quatro Barras } \\
\text { (PR) }\end{array}$ & \\
\hline Cerejeiras (RO) & Jaboticabal (SP) & Otacílio Costa (SC) & $\begin{array}{l}\text { Rondonópolis } \\
\text { (MT) }\end{array}$ & \\
\hline
\end{tabular}

Fonte: Os autores (2019).

Os resultados concordam com Brasil (2019), ao constatar predominância desse tipo de prática remuneratória na região Sul do país. Campos (2012), investigando a relação entre a existência de cobrança e geração de RSU, identificou que essa é a região brasileira com maior incidência de municípios que realizam a cobrança pelos serviços e menor geração de RSU, aventando que a remuneração pelo serviço pode inibir a geração de RSU.

Sauer, Parizková e Hadrabová (2008), em estudo realizado na República Tcheca, verificaram o impacto positivo da cobrança na segregação domiciliar dos resíduos, enquanto que Wu, Zhang, Xu e Che (2015), na China, mediante a curva ambiental de Kuznets, constataram que a cobrança pelos serviços impactou na minimização da geração de resíduos.

Para os entes do CGIRS-VJ, Ceará (2018b), recomenda que a cobrança seja feita de maneira progressiva e que a base de cálculo leve em consideração as seguintes variáveis: (i) custo pelos serviços; (ii) uso de imóvel (se domiciliar ou não domiciliar); e região onde o imóvel se localiza (urbana ou rural), que, para fins desse estudo, será denominada (iii) qualidade regional/pavimentação. 
Essas variáveis estão entre as mais usuais na amostra verificada, quais sejam: (i) uso/atividade do imóvel; (ii) custo pelo serviço; (iii) área do imóvel; (iv) frequência da coleta; (v) potencial de geração; e (vi) qualidade regional/pavimentação, vide Figura 2.

Figura 2 - Variáveis que compõem bases de cálculo para a cobrança pelos serviços de resíduos sólidos em municípios brasileiros.

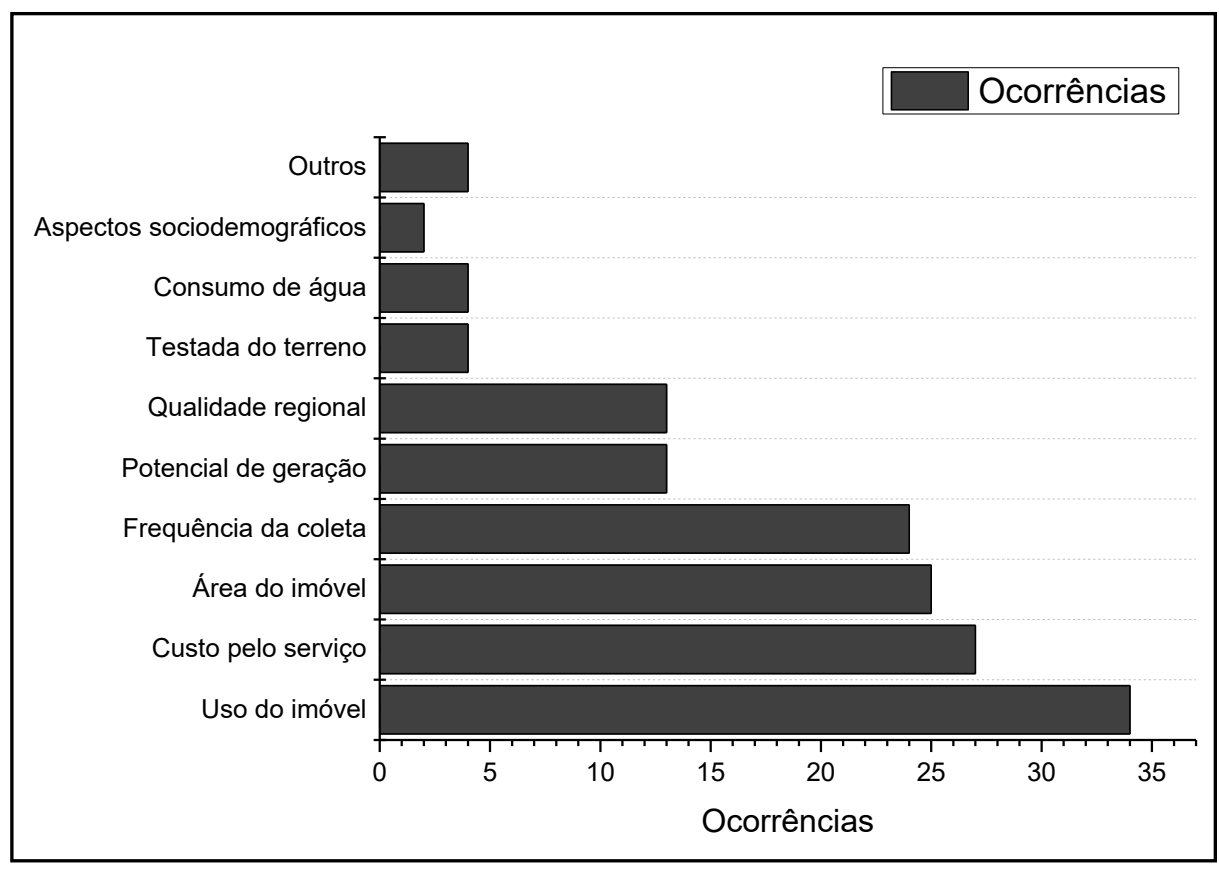

Fonte: Os autores (2019).

Ventura e Shibassaki (2016) também encontraram o uso do imóvel, custo pelo serviço, área do imóvel e frequência de coleta, respectivamente, como as quatro variáveis mais recorrentes em seu estudo, que envolvia 10 municípios, cuja justificativa utilizada para a cobrança, mediante os planos municipais de saneamento básico e/ou planos municipais de gestão integrada de resíduos sólidos verificados, foi a falta de recursos municipais destinados ao setor de limpeza pública urbana para melhorar a GIRS.

Para garantir a SEF do serviço, considerando as variáveis sugeridas para compor a base de cálculo nos entes do CGIRS-VJ, faz-se necessário refletir sobre elas, a começar pelo uso/atividade do imóvel, a mais recorrente na amostra investigada.

De acordo com as legislações verificadas, esta variável define se o imóvel é domiciliar, comercial, industrial e/ou misto, onde sua utilização poderá catalisar esforços para o correto cadastramento e fiscalização, desde a construção até as renovações de alvarás de funcionamento.

A depender de futuras legislações, que possam vir a ser aprovadas nos entes do CGIRS$\mathrm{VJ}$, alguns estabelecimentos poderão ter seus alvarás condicionados ao plano de gerenciamento de resíduos sólidos, por exemplo. 
A variável custo pelo serviço aponta relação diretamente proporcional entre os valores a serem pagos e a quantidade de toneladas a serem aterradas, podendo favorecer campanhas permanentes de educação ambiental, com ênfase na não geração, redução e reutilização, podendo subsidiar estratégias em busca da reinserção de alguns materiais, mediante acordos setoriais e logística reversa, na cadeia produtiva ou outra forma de destinação adequada.

A qualidade regional/pavimentação foi a sexta variável mais recorrente nas legislações verificadas. A inserção dessa variável fará chamamento ao diálogo entre a gestão de resíduos sólidos e o Plano Diretor municipal, revelando a necessidade do planejamento intersetorial, conforme preconizado pelo marco regulatório do saneamento.

Assim, considerando essa base de cálculo, é possível vislumbrar os desafios ${ }^{10}$ e esforços necessários para superá-los por parte da municipalidade e, dessa forma, tentar garantir preços cada vez mais módicos aos usuários.

De acordo com Ceará (2018b), os valores ${ }^{11}$ poderão variar de R $\$ 11,40$, no município de Morada Nova, a R\$29,20, em Ereré, considerando os domicílios urbanos e fazendo referência não apenas ao transbordo e disposição, mas também a receitas necessárias à universalização.

Ademais, comparou-se os indicadores socioeconômicos dos entes do CGIRS-VJ (Tabela 1) com os dos municípios pertencentes ao Grupo II, cujas informações se encontram na Tabela 2.

Tabela 2 - Características socioeconômicas de municípios do Grupo II.

\begin{tabular}{|c|c|c|c|c|c|}
\hline M unicipio & Estado & Pop. E stimad a (2018) & ID $\mathrm{H}$ & GINI & $\begin{array}{c}\text { PIB Per Capita } \\
\text { (RS) }\end{array}$ \\
\hline Caraá & RS & 8187 & 0,652 & 0,4106 & 12158,07 \\
\hline Cerejeiras & $\mathrm{RO}$ & 16444 & 0,692 & 0,4996 & 22721,08 \\
\hline Inocência & MS & 7625 & 0,681 & 0,4893 & 32069,52 \\
\hline Mandirituba & PR & 26411 & 0,655 & 0,4767 & 21729,50 \\
\hline Nioaque & MS & 14085 & 0,639 & 0,5968 & 17682,01 \\
\hline Otacilio Costa & $\mathrm{SC}$ & 18510 & 0,740 & 0,4161 & 34900,89 \\
\hline Piên & PR & 12606 & 0,694 & 0,4322 & 56085,51 \\
\hline Pomerode & $\mathrm{SC}$ & 32874 & 0,780 & 0,3765 & 53800,93 \\
\hline Quitandinha & PR & 18873 & 0,680 & 0,4853 & 16390,60 \\
\hline Quatro Barras & PR & 23199 & 0,742 & 0,4915 & 55692,28 \\
\hline Tijucas do Sul & PR & 16646 & 0,636 & 0,4833 & 21838,91 \\
\hline
\end{tabular}

Fonte: IBGE (2019) (adaptado).

Identificou-se diferença estatisticamente significativamente entre as médias do PIB per capita $(p<0,01 ; \mathrm{t}(22)=-4,49)$ e do IDH $(p<0,01 ; \mathrm{t}(22)=-3,28)$, apontando que as médias desses indicadores Grupo II superam as médias dos entes do CGIRS-VJ.

As diferenças socioeconômicas entre entes consorciados que já realizam a cobrança pelo serviço no Brasil, o fato dos entes do CGIRS-VJ estarem localizados na região brasileira com menor incidência de remuneração e de se encontram nos estratos populacionais onde também há menor tradição remuneratória, de acordo com Brasil (2019), põe a instituição de cobrança

\footnotetext{
${ }^{10}$ Os municípios cearenses não possuem entendimento claro a respeito de seu papel na gestão dos resíduos e na atuação dos consórcios, não assumindo a liderança, ficando a mercê da intervenção do estado (MELO, 2017).

${ }^{11}$ Menezes, Saiani e Toneto Jr (2014) afirmam que a cobrança pelo serviço em aranjos consorciados tende a reduzir menos a renda da população do que em soluções individuais.
}

DRd - Desenvolvimento Regional em debate (ISSNe 2237-9029) 
pelos consortes como algo pioneiro e desafiador, colocando-os em caráter de vanguarda no Nordeste.

Porém, não se pode descartar o custo vanguarda, que passa, impreterivelmente, pela ruptura de paradigmas políticos e culturais e do próprio modus operandi da gestão pública local, sendo necessárias estratégias que possibilitem desde o envolvimento da comunidade, educação ambiental, à efetivação da cobrança e avaliação de seus modelos, de modo a garantir o pleno funcionamento dos equipamentos, sempre mantendo o cuidado com a base de cálculo, para que os possíveis valores não violem os níveis de renda dos usuários, ao passo que garanta a SEF, conforme preconizado pela Lei Federal n 12.305/2010 (BRASIL, 2010).

Para tal, faz-se necessário investigar a capacidade de pagamento do usuário/disposição a pagar pelos serviços, cuja recomendação já fora feita pelo Ministério Público Estadual e acatada pela Assembleia Geral dos Prefeitos para que o CGIRS-VJ realize esse estudo (LIMOEIRO DO NORTE, 2018).

No Cariri cearense, por exemplo, estudos desta natureza foram realizados. Araújo et al (2018) encontraram disposição a pagar mediana no valor de $\mathrm{R} \$ 5,86$ habitante/mês, correspondente a 0,34\% da renda média mensal individual. Já Feitosa et. al. (2018), que pesquisaram a disponibilidade média a pagar pela coleta seletiva, em Juazeiro do Norte, apresentaram uma média de R \$ 15,70/mês, relacionando a maior ou menor disposição a pagar às variáveis gênero, renda e educação.

\section{CONSIDERAÇÕES FINAIS}

A PERSCE estipulou, até 2020, que 20\% de seus municípios estejam organizados em consórcios públicos e que, para atingir a SEF, determinou que o mesmo quantitativo de municípios também realize cobrança pelo serviço de maneira desvinculada ao IPTU.

Considerando o atual cenário, identificou-se que, quando comparada a realidades semelhantes no Brasil, as variáveis recomendadas para que façam parte da base de cálculo estão ajustadas, porém, ao comparar as variáveis socioeconômicas, percebe-se diferença estatisticamente significativa no que tange à riqueza produzida no município e à qualidade de vida municipal, entre os entes do CGIRS-VJ e os municípios brasileiros que realizam cobrança de maneira desvinculada do IPTU.

Assim, é possível aventar que, para a efetivação da remuneração pelos serviços nos entes do CGIRS-VJ, serão necessárias estratégias técnicas e políticas, para que se possa garantir a SEF da prestação dos serviços, adequadamente às condições dos usuários, uma vez que o cenário que se avizinha põe os municípios como pioneiros; seja pela nomeada falta de tradição da cobrança na região Nordeste do País; pela pouca prática em municípios brasileiros com esse porte populacional; ou, ainda, pela inexistência de cobrança nesses moldes no Estado. 


\section{REFERÊNCIAS}

ARAÚJO, R. C. P. de et al. Disposição a pagar pelo aterro sanitário da microrregião do Cariri, Ceará, Brasil. Revista Econômica do Nordeste. Fortaleza, v. 49, n. 3, p. 23-37, jul./set., 2018. Disponível em: $<$ https://ren.emnuvens.com.br/ren/article/viewFile/710/729>. Acesso em: 15 jan. 2019.

BNDES (BANCO NACIONAL DE DESENVOLVIMENTO ECONÔMICO E SOCIAL). Estimativa de investimentos em aterros sanitários para atendimento de metas estabelecidas pela Política Nacional de Resíduos Sólidos entre 2015 e 2019. 2015.

Disponível em: $<$ https://web.bndes.gov.br/bib/jspui/bitstream/1408/3041/2/

Estimativa $\% 20 \mathrm{de} \% 20 \mathrm{investimentos} \% 20 \mathrm{em} \% 20$ aterros $\% 20$ sanitarios_P.pdf $>$. Acesso em: 04 jul. 2019.

BRASIL. Instituto Brasileiro de Geografia e Estatística (IBGE). Cidades. Disponível em: $<$ https://cidades.ibge.gov.br>. Acesso em: 03 abr. 2019.

Lei $\mathbf{n}^{\mathbf{0}}$. 11.445, de 05 de janeiro de 2007. Estabelece diretrizes nacionais para o saneamento básico; altera as Leis nos 6.766, de 19 de dezembro de 1979, 8.036, de 11 de maio de 1990, 8.666, de 21 de junho de 1993, 8.987, de 13 de fevereiro de 1995; revoga a Lei no 6.528 , de 11 de maio de 1978; e dá outras providências.

Lei $\mathbf{n}^{0}$ 12.305, de 02 de agosto de 2010. Dispõe sobre a Política Nacional de

Resíduos Sólidos e dá outras providências. Legislação Federal. Disponível em:

$<$ http://www.planalto.gov.br>. Acesso em: 02 abr. 2019.

Ministério das Cidades. Sistema Nacional de Informações sobre Saneamento (SNIS).

Diagnóstico de Manejo de Resíduos Sólidos Urbanos (2017). Disponível em:

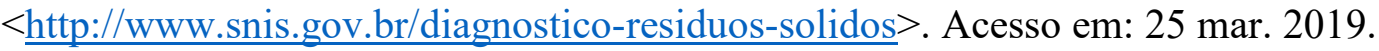

CAMPOS, H. K. T. Renda e evolução da geração per capita de resíduos sólidos no Brasil.

Engenharia. Sanitária e Ambiental. Rio de Janeiro, v. 17, n. 2, p. 171-180, jun. 2012. DOI: http://dx.doi.org/10.1590/S1413-41522012000200006. Disponível em:

$<$ http://www.scielo.br/scielo.php?script=sci_arttext\&pid=S1413-

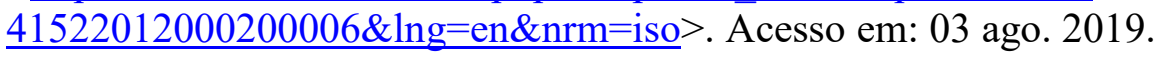

CEARÁ. Instituto de Pesquisa e Estratégia Econômica do Ceará (IPECE). Informe n⿳ $\mathbf{1 4 2}^{\text {: }}$ PIB dos municípios cearenses (2016), dez. 2018. Disponível em: <www.ipece.ce.gov.br>. Acesso em: 02. abr. 2019.

Secretaria das Cidades. Estudo financeiro para instituição de taxa a ser cobrada aos usuários pelo serviço de manejo de resíduos sólidos municipais (Produto 04). 2018.

Plano Estadual de Resíduos Sólidos. 2016. Disponível em:

$<$ https://www.sema.ce.gov.br/plano-estadual-de-residuos-solidos-2/>. Acesso em: 31 mar. 2019 .

DRd - Desenvolvimento Regional em debate (ISSNe 2237-9029) 
FEITOSA, A. K et al. Economic valuation in selective solid waste collection. Revista Sustentabilidade em Debate, v. 9, n. 3, p. 171-184, 2018.

\section{LIMOEIRO DO NORTE. Ata da Assembleia Geral Extraordinária dos Prefeitos do}

CGIRS-VJ, de 28 de novembro de 2018. Diário Oficial do Município. Ano II. N 418, de 21 de dezembro de 2018. Disponível em: $<$ https://www.limoeirodonorte.ce.gov.br/ diariolista.php>. Acesso em: 03 jun. 2019.

MAIA, C. V. de A et al. Distribuição espacial de criadouros de Aedes aegypti em Jaguaruana - Ce - Brasil e suas correlações com indicadores sociodemográficos. Revista Brasileira de Geografia Médica e da Saúde, v. 15, n. 31, p. 71 - 81, 9 jul. 2019. DOI: https://doi.org/10.14393/Hygeia153146811.

MANNI, L. A.; RUNHAAR, H. A. C. The social efficiency of pay-as-you-throw schemes for municipal solid waste reduction: A cost-benefit analysis of four financial incentive schemes applied in Switzerland. Journal of Environmental Assessment Policy and Management, v. 16, n. 1. abr. 2014.

MARDER, M. et al. Análise da influência do Produto Interno Bruto (PIB) e da população urbana na geração per capita de resíduos sólidos em municípios do interior do RS, Brasil.

Revista Gestão e Sustentabilidade Ambiental, v. 7, n. 3. p. 21-35, 2018. DOI:

http://dx.doi.org/10.19177/rgsa.v7e3201821-35.

MELO, Á. J. M. Consórcios públicos intermunicipais de manejo de resíduos sólidos urbanos no Estado do Ceará. Revista da Procuradoria Geral do Município de Fortaleza, v. 25, p. 1, 2017. Disponível em: < $\underline{\text { http://revista.pgm.fortaleza.ce.gov.br/index.php/revista1/ }}$ article/view/351/265>. Acesso em: 14 abr. 2019.

MENEZES, R. T.; SAIANI, C. C. S.; TONETO JUNIOR, R. Construção e operação de aterros sanitários: vantagem dos consórcios municipais. In: TONETO JUNIOR, R.; SAIANI, C. C. S.; DOURADO, J. (Org). Resíduos sólidos no Brasil: oportunidades e desafios da Lei Federal n 12.305 (Lei de Resíduos Sólidos). Barueri, SP: Manole, 2014, p. 383 - 423.

PEREIRA, G. A.; MOREIRA, T. B. S. Consórcios Públicos Intermunicipais: características dos municípios participante. Revista de Políticas Públicas. São Luís, v. 20, n. 1. p. 307-326, jan./jul. 2016. DOI: http://dx.doi.org/10.18764/2178-2865.v20n1p307-326.

PISANI JUNIOR, R.; CASTRO, M. C. A. A.; COSTA, A. Á. Desenvolvimento de correlação para estimativa da taxa de geração per capita de resíduos sólidos urbanos no estado de São Paulo: influências da população, renda per capita e consumo de energia elétrica. Engenharia Sanitária e Ambiental, Rio de Janeiro, v. 23, n. 2, p. 415-424, mar. 2018. DOI: http://dx.doi.org/10.1590/s1413-41522018167380.

SAIANI, C. C. S; TONETO JUNIOR, R. Manejo de resíduos sólidos no Brasil: desigualdades e efeitos sobre a saúde. In: TONETO JUNIOR, R.; SAIANI, C. C. S.; DOURADO, J. (Org).

Resíduos sólidos no Brasil: oportunidades e desafios da Lei Federal n 12.305 (Lei de Resíduos Sólidos). Barueri, SP: Manole, 2014. p. 3 - 53. 
SAIANI, C. C. S; TONETO JUNIOR, R.; DOURADO, J. Desigualdade de acesso a serviços de saneamento ambiental nos municípios brasileiros: evidências de uma Curva de Kuznets e de uma Seletividade Hierárquica das Políticas? Nova economia, Belo Horizonte, v. 23, n. 3, p. 657-692, dez. 2013. DOI: http://dx.doi.org/10.1590/S0103-63512013000300006.

ŠAUER P.; PAŘÍZKOVA L.; HADRABOVÁ A. Charging systems for municipal solid wasted: experience from the Czech Republic. Waste Management, v. 28, n. 12. p. 2772 2777. sep. 2018. DOI: 10.1016/j.wasman.2008.03.030.

SOBRAL, M. F. F.; SOBRAL, A. I. G. P. Casos de dengue e coleta de lixo urbano: um estudo na Cidade do Recife, Brasil. Ciência \& saúde coletiva, Rio de Janeiro, v. 24, n. 3, p. 10751082, mar. 2019. DOI: http://dx.doi.org/10.1590/1413-81232018243.10702017.

VENTURA, K. S.; SHIBASSAKI, K. Estudo de método de cobrança de resíduos sólidos em municípios brasileiros. In: CONGRESSO BRASILEIRO DE GESTÃO AMBIENTAL. 7. nov. 2016. Campina Grande, PB. Anais... Campina Grande, PB, 2016. Disponível em: $<$ https://www.ibeas.org.br/congresso/Trabalhos2016/III-080.pdf $>$. Acesso em: 30 mar. 2019.

YUANG, H.; HUANG, Z.; XU, P. A frameword for eco-efficiency of C\&D Waste. Procedia Environmental Sciences, v. 31, p. 855-859, 2016. DOI:

https://doi.org/10.1016/j.proenv.2016.02.097. 